\title{
Ultra-weak photon emission: a nondestructive detection tool for food quality and safety assessment
}

\author{
Mohammad Amin Nematollahi ${ }^{1, *}$, Zahra Alinasab ${ }^{2}$, Seyed Mehdi Nassiri ${ }^{1}$, Amin Mousavi Khaneghah ${ }^{3, *}$ \\ ${ }^{1}$ Department of Biosystems Engineering, College of Agriculture, Shiraz University, Shiraz, Iran; ${ }^{2}$ Department of Medical \\ Physics, Isfahan University of Medical Sciences, Isfahan, Iran; ${ }^{3}$ Department of Food Science, Faculty of Food Engineering, \\ University of Campinas (UNICAMP), São Paulo, Brazil
}

"Corresponding Authors: Mohammad Amin Nematollahi, Department of Biosystems Engineering, College of Agriculture, Shiraz University, Shiraz, Iran. Email: manema@shirazu.ac.ir; Amin Mousavi Khaneghah, Department of Food Science, Faculty of Food Engineering, University of Campinas (UNICAMP), Rua Monteiro Lobato, 80. Caixa Postal: 6121.CEP: 13083-862, Campinas, São Paulo, Brazil. Email: mousavi@unicamp.br

Received: 11 June 2020; Accepted: 26 September 2020; Published: 16 October 2020

(c) 2020 Codon Publications

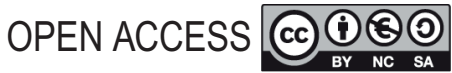

REVIEW ARTICLE

\begin{abstract}
A new aspect covering interactions between cells and their surroundings via electromagnetic waves was introduced by applying ultra-weak photon emission (UPE). The UPE originates from the relaxation of electronically excited species resulting from oxidative metabolic processes and oxidative stress associated with reactive oxygen species (ROS). The ROS plays a critical role in the quality of foods, and their determination is of extreme importance. The ROS and the intensity of the UPE have significantly correlated. The UPE can be effectively monitored by specific instruments such as photomultiplier tube and charged-coupled devices. The current review is devoted to providing an overview of the quality of food products by the aid of UPE via evaluating the correlations between UPE and food quality indices. In this regard, the UPE can be utilized in food quality as a real-time, noninvasive, and nondestructive technique without complex instruments. However, the implementation of the UPE method for evaluation of food quality needs further investigations.
\end{abstract}

Keywords: defense mechanisms; food quality assessment; oxidative stress; reactive oxygen species; ultra-weak photon emission

\section{Introduction}

All known biological systems possess an active oxidative metabolism or stress that involves oxidation reactions in which reactive oxygen species (ROS) play a critical role. These ROS can efficiently react with biomolecules in organisms, resulting in the synthesis of unstable intermediates. The decomposition of these intermediates mostly leads to the formation of unstable excited electron species. During this formation, a tiny amount of light is generated, and monitoring of this light can give essential information about the organism's oxidative state (Cifra and Pospišil, 2014; Pospíšil et al., 2014).
Investigations regarding cellular communication through ultra-weak photon emission (UPE) started in the 1910s. At that time, a scientist named Alexander Gurwitsch, after conducting various experiments revealed that two separate series of onion root cell cultures, adjacent to each other, could pose some influences on each other regarding cell division and multiplication rate (Bischof, 2003; Prasad et al., 2014; Scholkmann et al., 2013).

The emission of light by various living organisms was demonstrated by several previous investigations (Burgos et al., 2017; Cifra and Pospíšil, 2014; de Mello Gallep and Robert 2020; Esmaeilpour et al., 2020; Jia et al., 2020; 
Prasad et al., 2014; Prasad et al., 2020; Van Wijk et al., 2001). According to literature, the concept of UPE was introduced in a variety of terms such as "biophotons," "ultra-weak emission," "self-bioluminescent emission," "photoluminescence," "delayed luminescence," “ultraweak luminescence," "spontaneous chemiluminescence," "endogenous bioluminescence," and "biochemiluminescence" (Salari et al., 2011; Shanei et al., 2017).

As very active and unstable compounds, free radicals are referred to as atoms, molecules, or ions with unpaired electrons (Mayorga Burrezo et al., 2019). In this regard, the oxygen radicals are classified as free radicals which can be produced continuously in all living organs with destructive effects on cellular proteins, lipids, and, most notably, DNA that may lead to carcinogenesis (Saikolappan et al., 2019). The ROS can be classified into two groups as radical and non-radical species (Gill and Tuteja, 2010; Pospíšil et al., 2019). The ROS can react with biomolecules, such as lipids, nucleic acids, and proteins, to cause a deformity and finally increase their levels of energy. Consequently, this reaction creates electron excitation, with later electron's transition from a singlet-triplet state to the base state with photon emission, usually called UPE (Pospíšil et al., 2014).

The formation of ROS in the food and agricultural industry must be monitored as it is strongly related to public health and may cause an economic burden at a global level. ROS production can be associated with monitoring plant response to pathogens, drought stress, flooding stress, salt stress, and herbicides among agriculture products. Currently, the evaluation of UPE as a robust, realtime, inexpensive, nondestructive, and noninvasive tool to monitor oxidative reactions among several scientific fields, such as medical, pharmaceutical, biological, environmental, agricultural, and food products, is the point of interest. A probable correlation between UPE and food quality indices can be proposed (Gałązka-Czarnecka et al., 2019; Sun et al., 2019). Therefore, the UPE as a diagnostic tool to monitor agriculture processes can be considered for further developments (Cifra and Pospíšil, 2014; Guo et al., 2017; Inagaki et al., 2008; Moraes et al., 2012; Prasad and Pospíšil, 2011).

Due to the rapid growth of the world population, food security, safety, and quality are important issues that should be considered severe challenges (Cheeseman, 2016; Godfray et al., 2010; McCarthy et al., 2018; Prosekov and Ivanova, 2018). Destructive methods are widely employed to evaluate food quality, but they are usually more labor-intensive and time-consuming, which may harm the material. In contrast, the nondestructive methods allow the measurement of different food quality attributes without affecting physical structure and quality. Therefore, the use of nondestructive methods has attracted many researchers (El-Mesery et al., 2019; Magwaza et al., 2013). Traditional nondestructive techniques, such as machine vision, hyper-spectral imaging, near-infrared (IR) spectroscopy, electronic nose, electronic eye, electronic tongue, ultrasound measurements, and acoustic emission measurements, have been employed to assess the quality of food and agricultural products (El-Mesery et al., 2019; Giovenzana et al., 2017; Kheiralipour et al., 2016; Omar and MatJafri, 2013; Schinabeck et al., 2018; Zhong and Wang, 2019).

Currently, the application of UPE in food quality is a hot topic, and investigations are still ongoing regarding measuring food quality indices. However, to the best of our knowledge, no overview of this subject in the food quality area has been provided. Therefore, this article was undertaken to provide an overview considering the measurement of ROS production by UPE in food quality assessment. In this context, the definition, sources of generation, detection mechanisms, and applications of UPE in agricultural products are pinpointed.

\section{Ultra-Weak Photon Emission}

\section{UPE definition}

In addition to chemical signal transduction pathways, the communication between living beings can be carried out through electromagnetic waves (Van Wijk, 2001). In this regard, they could emit light either spontaneously or coherently, which is different from fluorescence, phosphorescence, and conventional bioluminescence (Cifra and Pospíšil, 2014; Shanei et al., 2017). The spontaneous emission can occur without an external excitation or any pre-illumination. The living organisms have a nonexponential decay of UPE after exposure to external light (Rafii-Tabar and Rafieiolhosseini, 2015). The coherent emission is another aspect of UPE, defined as a state of light in which waves can interfere constructively and form interference patterns (Gu, 1999).

As mentioned earlier, the oxidation of biomolecules during cellular metabolism leads to UPE. It was also reported that an organism's DNA could act as a source of UPE (Prasad et al., 2014).

Induced UPE can be originated from various oxidative factors, mainly biotic and abiotic stresses. The biotic factors include bacterial (Mansfield, 2005), viral (Kobayashi et al., 2006), fungal (Rastogi and Pospíšil, 2012), and herbivorous stress (Yoshinaga et al., 2006). The abiotic stresses arise from factors such as the surrounding environment (Münzel et al., 2018), mechanical damage 
(Liang et al., 2019), undesired temperature (Ahammed et al., 2019), light (Nakashima et al., 2017), and ionizing radiation (Singh et al., 2017). All these factors increase oxidative damages because of excessive production of ROS. The UPE possesses a spectral range varying from 200 to $800 \mathrm{~nm}$ with fragile intensity (few to hundreds of photons per $\mathrm{cm}^{2}$ ) (Yang et al., 2017). It is interesting to note that such intensity of radiation is equivalent to look at candlelight with naked eyes from a distance of nearly $24 \mathrm{~km}$ (Bischof, 2005), which elucidates the difficulty of capturing these signals.

\section{UPE detection}

The photographic containers and tubes with a particular sensibility to ultraviolet (UV) rays were the first employed devices for UPE detection, capturing waves in the UV range (Cifra et al., 2011). However, the intensity of these waves was very weak for such detection with available detectors. Therefore, their detection was postponed for many years. After some advancements in technology, several suitable devices were introduced to detect UPE, for example, avalanche photodiodes (APD), photodiode arrays (PDA), charged-coupled devices (CCD), microchannel plate (MCP), visible light photon counters (VLPC), superconducting tunnel junctions (STJ), hybrid photon detector (HPD), photo multiplier-tube (PMT), and channel photomultiplier (CPM). PDAs, CCDs, and MCPs, are used for spatial (2-dimensional [2D]) resolution. Considering the devices introduced for $1 \mathrm{D}$ resolution, PMTs deal with a characteristic photon density ranging from a few to up to some hundred photons per square centimeter per second. Therefore, they remain a suitable choice for UPE detection. After PMT development in the 1950s, detection of this light achieved notable improvement, and measurements became accurate (Bischof, 2005; Rahnama et al., 2011). At this stage, scientists discovered that UPE was also emitted in the visible range and UV range. Up to now, PMT and CCD cameras have been used widely for the detection of UPE (Cifra et al., 2011). While the former enhances light radiation up to 100 times, the latter detects this light in two dimensions as a highly sensitive photon detector. The MCP devices are sensitive compared with PDA and CCD (Madl, 2014; Ortega-Ojeda et al., 2018).

\section{Effect of ROS on Plants}

\section{Oxidative stress}

Oxidative stress is defined as "an imbalance between oxidant production by free radicals and the antioxidant capacity of the cell" (Sies et al., 2017), which causes severe adverse effects on the growth and productivity of plants. The biotic, abiotic, and stress conditions (Pitzschke et al., 2006) are demonstrated in Figure 1. ROS are free radicals and play a critical role in oxidative stress in which their accumulation in the plant cell leads to damage to some organelles. Besides, along with ROS, reactive nitrogen and sulfur species play an essential role in the cell's oxidative stress development.

\section{ROS formation}

Reactive oxygen species in all aerobic organisms, as well as plants, are continuously formed as a toxic by-product as a result of aerobic metabolism, while they also can be originated from various enzymatic and nonenzymatic processes as well as two biotic and abiotic factors (Bailey-Serres and Mittler, 2006; Gupta et al., 2015). While the sources of ROS in plant cells are located in chloroplasts, mitochondria, peroxisomes, endoplasmic reticulum, apoplast, plasma membranes, and cell wall (Abouzari and Fakheri, 2015), some ROS can be detoxified by some enzymatic and nonenzymatic mechanisms

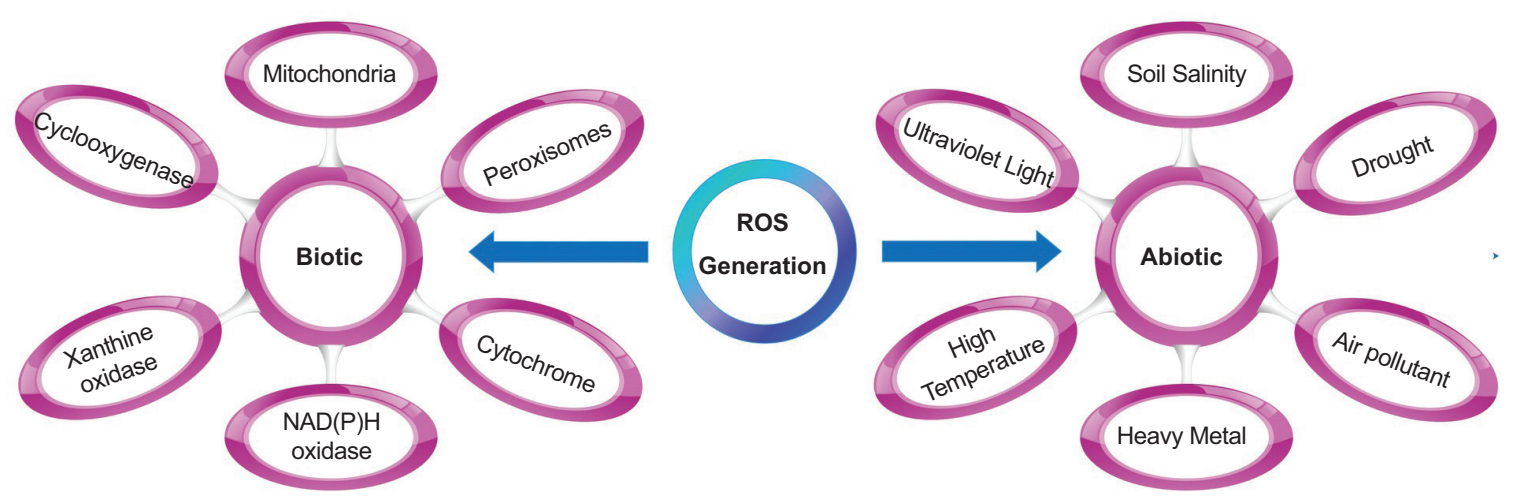

Figure 1. Sources of ROS generation. ROS, reactive oxygen species. 
(Ahmad, 2013). Figure 2 demonstrates the radical and non-radical forms of ROS.

The reactions for significant ROS generation can be summarized as follows:

$$
\begin{gathered}
\mathrm{O}_{2}+\mathrm{e}^{-} \rightarrow \mathrm{O}_{2}^{--} \\
2 \mathrm{O}_{2}^{--}+2 \mathrm{H}^{+} \rightarrow \mathrm{H}_{2} \mathrm{O}_{2}+\mathrm{O}_{2} \\
\mathrm{O}_{2}+h v \rightarrow{ }^{1} \mathrm{O}_{2} \\
\mathrm{Fe}^{2+}+\mathrm{H}_{2} \mathrm{O}_{2} \rightarrow \mathrm{Fe}^{3+}+\cdot \mathrm{OH}+\mathrm{OH}^{-} \\
\mathrm{Cu}^{+}+\mathrm{H}_{2} \mathrm{O}_{2} \rightarrow \mathrm{Cu}^{2+}+\cdot \mathrm{OH}+\mathrm{OH}^{-} \\
\mathrm{O}_{2}^{\cdot-}+\mathrm{H}_{2} \mathrm{O}_{2} \rightarrow \cdot \mathrm{OH}+\mathrm{OH}^{-}+\mathrm{O}_{2}
\end{gathered}
$$

The one-electron reduction of molecular oxygen is responsible for forming high-reactive superoxide radicals (Equation 1). This reduction occurs in mitochondria, chloroplasts, and peroxisomes (Pospíšil et al., 2019). Unlike the superoxide radical, hydrogen peroxide, which is formed through a dismutation reaction by superoxide dismutase (SOD) enzyme, is relatively stable and less reactive (Equation 2) (Battin and Brumaghim, 2009). Hydrogen peroxide can also be produced by different enzymes, such as glycolate oxidase, L-amino acid oxidase, and urate oxidase (Battin and Brumaghim, 2009; Thannickal and Fanburg, 2000). Singlet oxygen, a non-radical, is an excited state of $\mathrm{O}_{2}$, which is not very reactive in its ground state (Equation 3 ). The chlorophyll and their precursors performed singlet oxygen's primary production (Krieger-Liszkay, 2005; Tripathy and Oelmüller, 2012). In the presence of transition metals (iron $\left[\mathrm{Fe}^{2+}\right]$ or copper $\left[\mathrm{Cu}^{2+}\right]$ ions), the highly reactive hydroxyl radical is formed (Equations 4 and 5) through the Fenton reaction (Battin and Brumaghim, 2009; Janků et al., 2019). Another source of hydroxyl radical is the Haber-Weiss reaction (Equation 6). The Haber-Weiss cycle is a two-step reaction. In the first step, the ferric $\left(\mathrm{Fe}^{3+}\right)$ ion reduction into the ferrous $\left(\mathrm{Fe}^{2+}\right)$ ion occurs via reaction with superoxide radical. The second step is the Fenton reaction (Equations 4 and 5). The first and second steps' net reaction is the Haber-Weiss reaction (Kehrer, 2000).

Under normal conditions, the ROS production rate in cells is low $\left(240 \mu \mathrm{mol} / \mathrm{s}\right.$ and $0.5 \mu \mathrm{mol} \mathrm{H}_{2} \mathrm{O}_{2}$ at a steadystate level), and the ROS generation is generally in balance with antioxidant capacity. When the oxidative stress exceeds the available antioxidants, the ROS generation's rate increases $\left(240-720 \mu \mathrm{mol} / \mathrm{s}\right.$ and 5-15 $\mu \mathrm{mol} \mathrm{H}_{2} \mathrm{O}_{2}$ in a steady-state level), which consequently, due to further accumulation, causes cell death when some adverse environmental factors perturb the balance between the rate of production and scavenging of ROS, the intracellular levels of ROS may rapidly rise (Pitzschke et al., 2006; Tsugane et al., 1999). Some defense mechanisms involved antioxidant agents that work hand in hand to reduce undesirable phenomenon (Racchi, 2013).

\section{Antioxidant defense mechanisms}

An antioxidant is a substance in low concentration that significantly inhibits oxidation or delays oxidation with different mechanisms (Mousavi Khaneghah, 2016). Among them, oxygen removal or localized oxygen reduction, removal of metal catalytic $\mathrm{Cu}^{2+}$ and $\mathrm{Fe}^{2+}$, removal of ROS such as $\mathrm{O}_{2}, \mathrm{H}_{2} \mathrm{O}_{2}$, and chain reaction interruptions, increase in the rate of ROS scavenging, acceleration of recovery of damaged cell structures, and enhancement of absorbed energy heat dissipation are mentioned in literature. Generally, an antioxidant's capacity to neutralize ROS action and free radicals depends on various factors

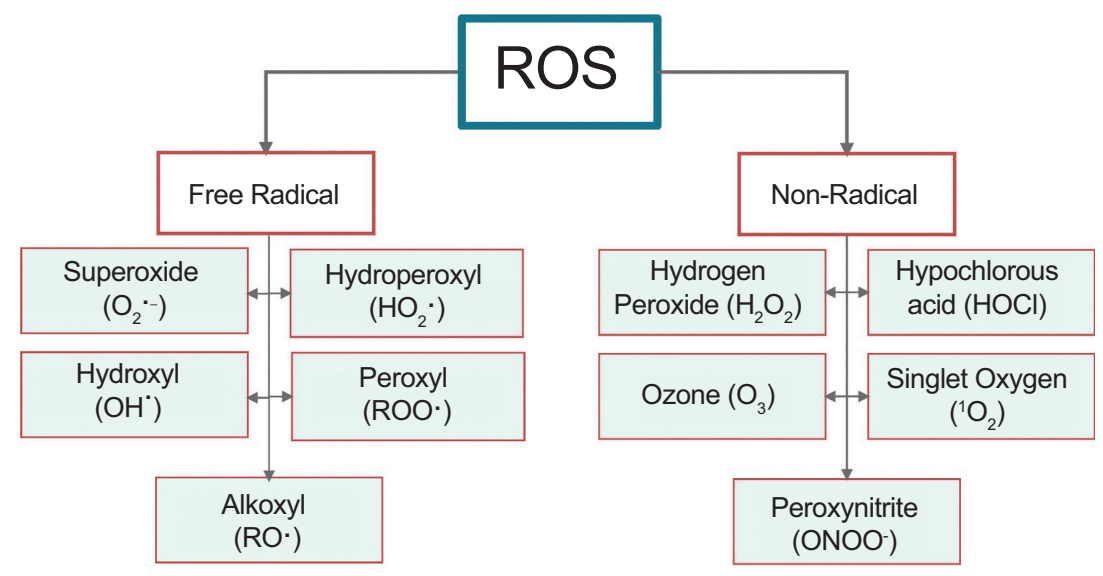

Figure 2. Radical and non-radical forms of ROS. ROS, reactive oxygen species 
such as activity, interaction with other antioxidants (synergetic), absorption, distribution, and metabolism of antioxidants (Pitzschke et al., 2006). Antioxidant systems can be classified into enzymatic and nonenzymatic groups (Table 1) (Caverzan et al., 2019; Karuppanapandian et al., 2011).

Recently, several studies have been carried out to find the effects of various antioxidants on UPE. The experimental evidence showed that the antioxidants suppressed UPE in various living organisms. For instance, the UPE from human skin was suppressed by three antioxidants (d- $\delta$-tocopherol sodium, L-glutathione, and L-ascorbate) (Tsuchida et al., 2019). Different antioxidants ( $\alpha$-tocopherol, glutathione, +6 ascorbate, and coenzyme Q10) notably decreased the UPE from the human skin (Rastogi and Pospísil, 2011). In another research, the results showed that the topical application of oligomeric proanthocyanidins (antioxidants) significantly reduced the UPE from the human skin (Van Wijk et al., 2010). Similar research on humans (Egawa et al., 1999; Sauermann et al., 1999) and mouse skins (Evelson et al., 1997) were conducted to find the effect of antioxidants UPE. It has also been shown that the UPE from radish root cells was considerably suppressed by different amounts of sodium ascorbate and cysteine (Rastogi and Pospísil, 2010). The ROS induced in rice cells by $N$-acetylchitooligosaccharide, and consequently UPE, was also highly suppressed by the addition of diphenyl iodonium as a ROS scavenger (Kageyama et al., 2006).

\section{Correlation between ROS and UPE}

All living systems are connected to their surroundings through the UPE exchange, while the spontaneous UPE is originated from the transition of electronically excited species to the ground state formed during oxidative metabolic processes (Pospíšil et al., 2014). Cyclo-addition of ${ }^{1} \mathrm{O}_{2}$ or the hydrogen abstraction ${ }^{\circ} \mathrm{HO}$ is two mechanisms for oxidation of biomolecules among oxidative metabolic processes. The hydrogen abstraction from proteins, nucleic acids, and lipids by $\mathrm{HO}^{\circ}$ can result in an alkyl radical ( $\left.\mathrm{R}^{\circ}\right)$, which could react with $\mathrm{O}_{2}$ and produce peroxy radical (ROO'). The cyclization of ROO' and the recombination of two ROO' lead to high-energy intermediates dioxetane (ROOR) and tetroxide (ROOOOR), respectively. The production of dioxetane is also performed by cycloaddition of singlet oxygen. The electronic species, such as triplet-excited carbonyls $\left({ }^{3} \mathrm{R}=\mathrm{O}^{*}\right)$, singlet $\left({ }^{1} \mathrm{P}^{*}\right)$, and triplet pigment $\left({ }^{3} \mathrm{P}^{\prime \prime}\right)$, and ${ }^{1} \mathrm{O}_{2}$ are formed due to the decomposition of tetroxide and dioxetane (Fedorova et al., 2007; Pospíšil et al., 2014; Yang et al., 2015).

The spectrum of the spectrum associated with photon emission of ${ }^{3} \mathrm{R}=\mathrm{O}^{*}(350-550 \mathrm{~nm})$ is near UV and
Table 1. Classification of important enzymatic and nonenzymatic antioxidants.

\begin{tabular}{|c|c|}
\hline \multicolumn{2}{|c|}{ ROS scavenging by antioxidant enzymes } \\
\hline Enzymes & Reactions \\
\hline SOD & $2 \mathrm{O}_{2}^{--}+2 \mathrm{H}^{+} \rightarrow \mathrm{H}_{2} \mathrm{O}_{2}+\mathrm{O}_{2}$ \\
\hline CAT & $2 \mathrm{H}_{2} \mathrm{O}_{2} \rightarrow 2 \mathrm{H}_{2} \mathrm{O}+\mathrm{O}_{2}$ \\
\hline POD & $\mathrm{H}_{2} \mathrm{O}_{2}+\mathrm{GSH} \rightarrow \mathrm{H}_{2} \mathrm{O}+\mathrm{GSSG}$ \\
\hline APX & $\mathrm{H}_{2} \mathrm{O}_{2}+\mathrm{ASCA} \rightarrow 2 \mathrm{H}_{2} \mathrm{O}+\mathrm{DHA}$ \\
\hline MDHAR & $2 \mathrm{MDHA}+\mathrm{NAD}(\mathrm{P}) \mathrm{H} \rightarrow 2 \mathrm{ASCA}+\mathrm{NAD}(\mathrm{P})$ \\
\hline DHAR & $\mathrm{DHA}+2 \mathrm{GSH} \rightarrow \mathrm{ASCA}+\mathrm{GSSG}$ \\
\hline GR & $\mathrm{GSSG}+\mathrm{NAD}(\mathrm{P}) \mathrm{H} \rightarrow 2 \mathrm{GSH}+\mathrm{NAD}(\mathrm{P})^{+}$ \\
\hline GPX & $\mathrm{H}_{2} \mathrm{O}_{2}+2 \mathrm{GSH} \rightarrow 2 \mathrm{H}_{2} \mathrm{O}+\mathrm{GSSG}$ \\
\hline \multicolumn{2}{|c|}{ ROS scavenging by antioxidant nonenzymes } \\
\hline Nonenzymes & Reactions \\
\hline AscA & Detoxifies $\mathrm{H}_{2} \mathrm{O}_{2}, \mathrm{O}_{2}^{--}$and ${ }^{*} \mathrm{OH}$ \\
\hline GSH & $\begin{array}{l}\text { Substrate for various PODs, GSTs, and GR. } \\
\text { Detoxifies } \mathrm{H}_{2} \mathrm{O}_{2} \mathrm{O}_{2}^{--} \text {, and "OH }\end{array}$ \\
\hline TOCs & $\begin{array}{l}\text { Protects membrane lipids from peroxidation, } \\
\text { detoxifies lipid peroxides, and quenching }{ }^{1} \mathrm{O}_{2}\end{array}$ \\
\hline CARs & Quench ${ }^{1} \mathrm{O}_{2}$ \\
\hline Flavonoids & Can directly scavenge $\mathrm{H}_{2} \mathrm{O}_{2}$ and $\mathrm{OH}^{\circ}$ \\
\hline
\end{tabular}

AscA: ascorbic acid; APX: ascorbate peroxidase;

CARs: carotenoids; CAT: catalase; DHA: dehydroascorbate; DHAR: dehydroascorbate reductase; GPX: guaiacol peroxidase; GR: glutathione reductase; GSH: glutathione; GSSG: oxidized glutathione; GSTs: glutathione-S-transferases;

MDHA: monodehydroascorbate; MDHAR: monodehydroascorbate reductase; PODs: peroxidases; SOD: superoxide dismutase; TOCs: tocopherols.

blue-green regions of visible light (Fedorova et al., 2007). The spectrum range of singlet- and triplet-excited pigments belongs to green-red (550-750 nm) and red-near IR (750-1000 nm), respectively (Pospíšil et al., 2014; Sauermann et al., 1999). The photon emissions of monomol ${ }^{1} \mathrm{O}_{2}$ and dimol are close to IR (at $1270 \mathrm{~nm}$ ) and the visible light (at 634 and $703 \mathrm{~nm}$ ), respectively (Adam et al., 2005; Pospíšil et al., 2014).

\section{UPE Application in Food and Agriculture}

As already discussed, UPE is produced and released by ROS and received by biological systems, especially in agriculture. However, how UPE is emitted and received in intercellular and intracellular interactions is still a significant issue. Since the detection and analysis of the UPE spectrum are simple, available, inexpensive, and noninvasive, it can be used in different fields.

As mentioned earlier, most experiments demonstrate the impact of UPE in the field of agriculture, which can be used for the detection of pathogens in plants (Bennett 
et al., 2005; Iyozumi et al., 2002; Kageyama et al., 2006; Kobayashi et al., 2006; Makino et al., 1996; Mansfield, 2005; Montillet et al., 2005; Rastogi and Pospíšil, 2012), drought stress (Guo and Tan, 2013; Kausar et al., 2012; Komatsu et al., 2014; Ohya et al., 2000), salinity (Ohya et al., 2000), flooding stress (Kamal and Komatsu, 2016; Kausar et al., 2012; Khatoon et al., 2012; Komatsu et al., 2014), and herbicides (Inagaki et al., 2007, 2008, 2009; Kato et al., 2014; Nukui et al., 2013).

\section{Food quality and safety with UPE}

As stated above, the studies on UPE in the areas of food quality are limited. The aim is to review the useful, relevant documents to find the relation between food quality and safety with UPE (Table 2).

For better clarity, the extensive description of each study (Table 2) follows.

The UPE method was employed to assess the quality of milk, hen's eggs, and vegetable oils. In the case of milk, to improve its durability, some heating methods were applied, resulting in a further decrease in the light storage capacity of milk and consequently lead to a change in its components and quality, such as protein denaturation dephosphorylation and loss of vitamins. For this purpose, some pasteurized, homogenized, and ultra-high temperature milk samples with different fat percentages were prepared. The samples were exposed to white, red, and blue lights (light illumination). The UPE was mostly increased after light illumination was applied to these samples. It was revealed that the higher the light storage capacity, the lower the intensity of UPE. Based on these findings, a decrease and increase in the milk's light storage with low fat (1.5\%) and natural fat content (3.5-3.8\%) were noted, respectively. In the case of eggs, the aim was to find the origin of eggs while the egg yolk's desired color attracted the consumers. To identify the origin of eggs, 325 brown hens were divided into four different groups: soil, soil with free-range on vegetation, cage, and sand.

Further chemical analysis showed that no significant differences between the groups were evident. Although the eggs from cages or soil exhibited a lower UPE rate than free-range eggs (on vegetation and sand), it demonstrated that the source of UPE is not a single chemical substance. In edible oil, 24 different types of sunflower oils were subjected to UPE measurement in three groups (without external illumination, after white and red lights illumination). The quality of sunflower oils is characterized by three-factor values, including light storage capacity, decomposition procedures (e.g., low quality of storage and aging), and the order's value in the sense of physiological and nutritional values. A high rate of UPE after red light illumination can be associated with decomposition procedures. The irradiation of food breaks chemical bonds and consequently forms radicals. By illumination with light, the electronically excited radicals fall to their base stats, and due to these different energy levels, the light is emitted. Therefore, food irradiation shows a much higher emission rate (higher by a factor of 50) after light illumination than nonirradiated ones (Lambing, 1992).

Another study aimed to monitor the UPE accompanying autoxidation and water-biopolymer interactions in cereal products using the CCD technique. While the hydration of cellulose, dextran, or starch chains resulted in the hydrogen-bond formation and, consequently, accumulation of the excitation energy, incorporating water into cereal products enhanced the UPE (Slawinska and Slawinski, 1997, 1998).

The quality of tomato fruit was studied using UPE measurement. The fruits were harvested at four maturity stages (green-orange, orange-red, light red, and red) with almost the same size and weight. They were stored at a particular temperature $\left(20^{\circ} \mathrm{C}\right)$ and humidity $(80 \%$ $\mathrm{RH}$ ) for 10 days. It was found that the UPE was directly related to harvest maturity. It was mentioned that UPE could be used as a nondestructive method to evaluate tomato quality (Triglia et al., 1998).

The UPE was measured for rice (Oryza sativa L.) seeds, which were stored during different years (1996, 1998, 1999, and 2001), and the correlation between the degree of aging of rice seeds and the intensity of UPE was noted. It was observed that the rice seeds stored for a shorter period had a stronger intensity of UPE in early imbibition. Moreover, a significant correlation was reported between the germination rates of rice seeds and the intensity of UPE (Chen et al., 2003).

The coffee seed viability was studied by the aid of a UPE measurement. For this purpose, six coffee seeds were selected to measure UPE after exposure to white light at a constant temperature $\left(22{ }^{\circ} \mathrm{C}\right)$. The germination rates were recorded on the 15 th and 30 th day. The proposed method with further investigations can promote advances in storing methods via the UPE technique (Gallep et al., 2004).

The quality parameters of differently cultivated carrots from an organic farm and conventional farms in Austria were studied for 5 years (1998-2003) with different quality assessment methods, including sensor tests, food preference tests with laboratory rats, decomposition tests, P-value determination, chemical analysis, and UPE. In this work, the carrot slices were put under a light bulb, 


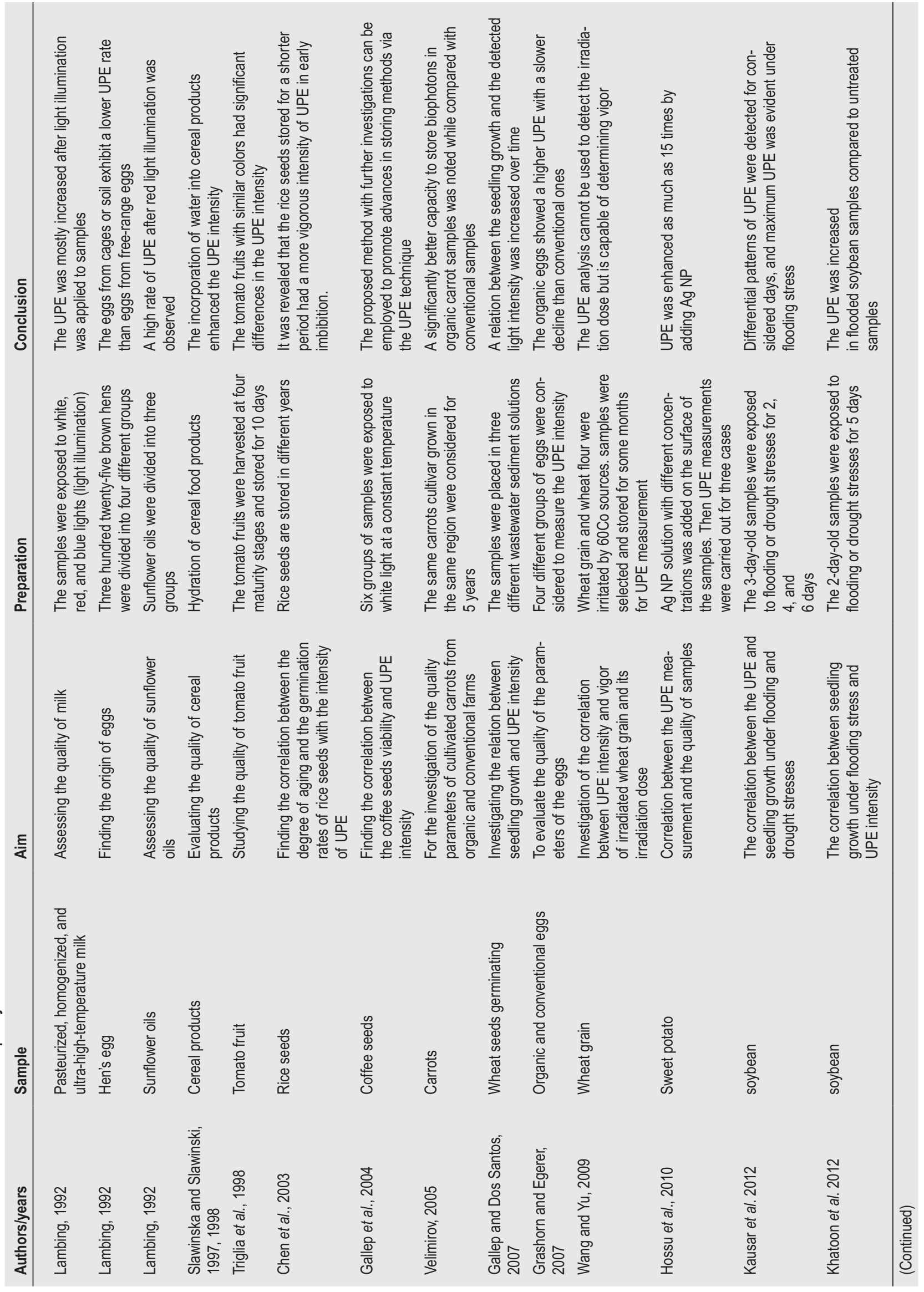




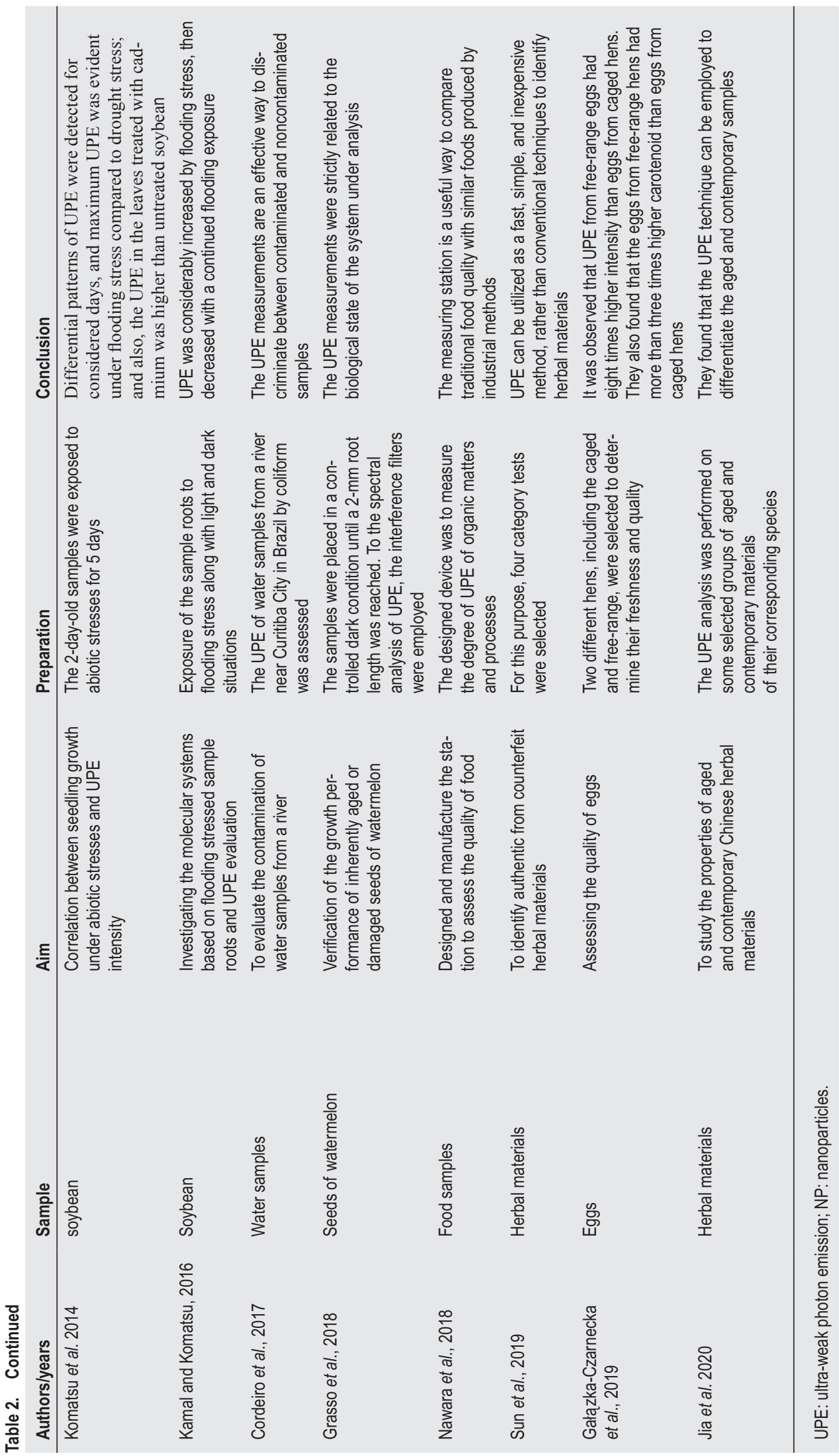


and UPE was measured. A significantly better capacity to store biophotons in organic carrot samples was compared with conventional samples (Velimirov, 2005).

The photon-counting of wheat seeds germinating in three different wastewater sediment solutions was analyzed using a PMT device, and correlation with seedling development was studied. It was indicated that there was an increasing relation between seedling growth and detected light intensity over time (Gallep and Dos Santos, 2007).

The quality of organic and conventional eggs (for 1 year) was investigated using a UPE measurement. In this regard, four different forms of production systems (barn, cage, organic, and free-range) were considered to evaluate the quality of eggs based on conventional (egg mass, shell-breaking strength, albumen height, the proportion of yolk, fatty acid profile, and yellow color) quality criteria and UPE measurements. The results depicted higher UPE with a slower declining trend for organic eggs. It was reported that the measurement of UPE could be a suitable method for evaluating the quality of organic eggs (Grashorn and Egerer, 2007).

Correlation between UPE intensity and vigor of irradiated wheat grain and its irradiation dose was investigated. At first, wheat grain and wheat flour were irritated by 60 Co sources with a dose rate of $1 \mathrm{kGy} / \mathrm{h}$, including 0 , $0.6,1.5,2.4$, and 3 kGy. Samples were stored for 0, 6, 12, and 18 months under commercial storage conditions for UPE measurement. In summary, UPE analysis could not detect irradiation dose but was capable of determining vigor (Wang and Yu, 2009).

Hossu et al. (2010) tried to find a relation between the UPE and sweet potato samples' quality. They selected eight sweet potato roots with 5-mm thick disk slices and an average of nine samples from each root. The samples were placed in a Petri dish with $8-\mathrm{mL} \mathrm{3 \%}$ sucrose (media). The samples were incubated for 1 week at a relative humidity of $90-95 \%$ and a temperature of $30{ }^{\circ} \mathrm{C}$ to increase storage quality. Different concentrations of the 2-mL solution of silver (Ag) nanoparticles (NP) were added on sweet potato samples' surfaces. Then UPE measurements were carried out for three cases (no media, media only, and adding Ag NP). They found that the UPE was enhanced by as much as 15 times by adding Ag NP. They mentioned that the UPE could provide useful information about the quality of biological material.

The relation between the UPE intensity and soybean seedling subjected to abiotic stresses was investigated. For this purpose, Kausar et al. (2012) (flooding and drought stresses), Khatoon et al. (2012) (flooding stress), and Komatsu et al. (2014) (flooding, drought, and cadmium stresses) considered 2 or 3-day-old seedling samples and exposed to stresses above. They measured the activity of the APX and isoflavone reductase, which have related to the UPE measurement. They found that differential patterns of UPE were detected for considered days, and maximum UPE was evident under flooding stress compared to drought stress, and the UPE in the leaves treated with cadmium was higher than untreated soybean samples.

Flooding is abiotic stress that influences plant growth and crop yields. Kamal and Komatsu (2016) investigated the molecular systems based on flooding-stressed roots in soybean and UPE evaluation under light and dark conditions. They found that the UPE was considerably increased with light and dark conditions after flooding stress but decreased with continued flooding exposure. They also showed that increase in the activity of enzyme lysine ketoglutarate reductase/saccharopine dehydrogenase bifunctional was due to flooding stress, which consequently increased ROS rate scavenging and UPE.

The UPE measurement for evaluating microbial contamination (coliform group) of water samples from a river near Curitiba City in Brazil was assessed. It was observed that the UPE measurement is an effective way to discriminate between contaminated and noncontaminated water samples (Cordeiro et al., 2017).

Grasso et al. (2018) verified the growth performance of inherently aged or damaged watermelon seeds by the UPE technique. For this purpose, they selected two lots of watermelon seeds, with 96 seeds in each lot. All the germination tests were performed using 12 dishes per lot, eight seeds in each dish, and a filter paper. To perform UPE measurements, the samples were placed in a controlled dark condition (at a temperature of $28.3^{\circ} \mathrm{C}$ ) until a 2-mm root length was reached. For the spectral analysis of UPE, the interference filters (Edmund Optics; center wavelength 450, 550, and $650 \mathrm{~nm}$, respectively) were employed. The results showed that the UPE measurements were strictly related to the system's biological state under analysis. They claimed that the proposed method could be used as a noninvasive and nondestructive technique for rapidly analyzing the seeds' viability and enhancing tools for seed-sorting systems.

Nawara et al. (2018) designed and manufactured a station to assess food quality. The designed device was to measure the degree of UPE of organic matters and processes. The manufactured instrument included a PC with counting, controlling systems, and measurements, including amplification and counting single photons (ESPC), control card, the light source for automatic recording of test results, and an application software created in the LabView environment. The measuring station 
was a useful way to compare traditional food quality with similar foods produced by industrial methods. This device can also measure the quality parameters of food products.

Interesting research was conducted by Sun et al. (2019) for quality control of herbal materials. They employed the UPE for identifying authentic from counterfeit herbal materials. For this purpose, they used four-category tests, which included (i) authentic versus counterfeit materials; (ii) authentic versus adulterated materials; (iii) authentic versus sulfur-fumigated materials, and (iv) authentic versus dyed materials. The authors found that the UPE could be utilized as a fast, simple, and inexpensive method for identification of herbal materials in comparison to conventional techniques such as morphological and microscopic methods, chromatography and spectrum photometer analyses, molecular biology assays, and biomimetic technologies (Chen et al., 2012; Xu et al., 2015).

Recently, the traditional and UPE methods were used for determining egg quality. Measured quality parameters were the color at the La Roche point-YCF scale, $\mathrm{pH}$, Haugh unit, and yolk color. Gałązka-Czarnecka et al. (2019) selected two different hens, including caged and free-range hens, with 60 eggs, yolk, and white, to determine the freshness and quality. Three yolks of each type of egg were mixed and considered as a sample. It was observed that UPE from eggs of free-range hens had eight times higher intensity than eggs from caged hens. The authors also found that the eggs of free-range hens had more than three times higher carotenoid than caged hens. They stated that further research is needed for using the UPE method as a food quality assessment tool.

Jia et al. (2020) studied the aged and contemporary properties of some Chinese herbal materials, including Glycyrrhiza glabra L., Glycyrrhiza inflata Batalin, Glycyrrhiza uralensis Fisch., Curcuma aromatica Salisb., Zingiber officinale Roscoe, Acorus calamus L., and Alpinia officinarum Hance. They implemented the UPE technique by PMT devices to differentiate the aged and contemporary samples. They found out that the UPE technique can be able to achieve the desired result. They also suggested that the UPE technique provides useful data on the storage time effect and the herbal medicines' quality assessment.

\section{Conclusion}

This review presents an overall framework on various aspects of UPE. Definition, detection techniques, and different applications of UPE were studied. The UPE results from the relaxation of the electronically excited species, resulting from oxidative metabolic and oxidative stresses.
Owing to the growing world population and food security, safety, and quality is imperative issues, the current study focuses on the applications of UPE on the subject of food quality. The proposed method with further investigations could open new horizons on many branches of sciences. This technique is non-invasive and nondestructive and a cheap, rapid, and real-time technique that does not need complex instrumentation.

\section{References}

Abouzari, A. and Fakheri, B.A., 2015. Reactive oxygen species: generation, oxidative damage, and signal transduction. International Journal of Life Sciences 9(5): 3-17. https://doi.org/10.3126/ijls. v9i5.12699

Adam, W., Kazakov, D.V. and Kazakov, V.P., 2005. Singlet-oxygen chemiluminescence in peroxide reactions. Chemical Reviews 105(9): 3371-3387. https://doi.org/10.1021/cr0300035

Ahammed, G.J., Xu, W., Liu, A. and Chen, S., 2019, Endogenous melatonin deficiency aggravates high temperature-induced oxidative stress in Solanum lycopersicum L. Environmental and Experimental Botany 161: 303-311. https://doi.org/10.1016/j. envexpbot.2018.06.006

Ahmad, P. (Ed.), 2013. Oxidative damage to plants-antioxidant networks and signaling. Elsevier, San Diego, CA.

Bailey-Serres, J. and Mittler, R., 2006. The roles of reactive oxygen species in plant cells. Plant Phsiology 141: 311. https://doi. org/10.1104/pp.104.900191

Battin, E.E. and Brumaghim, J.L., 2009. Antioxidant activity of sulfur and selenium: a review of reactive oxygen species scavenging, glutathione peroxidase, and metal-binding antioxidant mechanisms. Cell Biochemistry and Biophysics 55(1): 1-23. https:// doi.org/10.1007/s12013-009-9054-7

Bennett, M., Mehta, M. and Grant, M., 2005. Biophoton imaging: a nondestructive method for assaying $\mathrm{R}$ gene responses. Molecular Plant-Microbe Interactions 18(2): 95-102. https:// doi.org/10.1094/MPMI-18-0095

Bischof, M., 2003. Introduction to integrative biophysics. In: Integrative biophysics. Springer, Dordrecht, Netherlands, pp. 1-115.

Bischof, M., 2005. Biophotons-the light in our cells. Journal of Optometric Phototherapy, pp. 1-5.

Burgos, R.C.R., Schoeman, J.C., van Winden, L.J., Červinková, K., Ramautar, R., Van Wijk, E.P., Cifra, M., Berger, R., Hankemeier, T. and van der Greef, J., 2017. Ultra-weak photon emission as a dynamic tool for monitoring oxidative stress metabolism. Scientific Reports 7(1):1-9. https://doi.org/10.1038/s41598-01701229-x

Caverzan, A., Piasecki, C., Chavarria, G., Stewart, C.N. and Vargas, L., 2019. Defenses against ROS in crops and weeds: the effects of interference and herbicides. International Journal of Molecular Sciences 20(5): 1086. https://doi.org/10.3390/ijms20051086

Cheeseman, J., 2016. Food security in the face of salinity, drought, climate change, and population growth. In: Halophytes for food security in dry lands. Academic Press, San Diego, USA, pp. 111-123. 
Chen, S., Guo, B., Zhang, G., Yan, Z., Luo, G., Sun, S., Wu, H., Huang, L., Pang, X. and Chen, J., 2012. Advances of studies on new technology and method for identifying traditional Chinese medicinal materials. Zhongguo Zhong yao za zhi= Zhongguo zhongyao zazhi $=$ China Journal of Chinese Materia Medica 37(8): 1043-1055. https://doi.org/10.4268/CJCMM20120801

Chen, W., Xing, D., Wang, J. and He, Y., 2003. Rapid determination of rice seed vigour by spontaneous chemiluminescence and singlet oxygen generation during early imbibition. Luminescence: The Journal of Biological and Chemical Luminescence 18(1): 19-24. https://doi.org/10.1002/bio.695

Cifra, M., Fields, J.Z. and Farhadi, A., 2011. Electromagnetic cellular interactions. Progress in Biophysics and Molecular Biology 105(3): 223-246. https://doi.org/10.1016/j.pbiomolbio.2010.07.003

Cifra, M. and Pospíšil, P., 2014. Ultra-weak photon emission from biological samples: definition, mechanisms, properties, detection and applications. Journal of Photochemistry and Photobiology B: Biology 139: 2-10. https://doi.org/10.1016/j. jphotobiol.2014.02.009

Cordeiro, A., Fabris, J., Couto, G., Kalinowski, H. and Bertogna, E., 2017. Water assessment using ultra-weak bioluminescence. Journal of Photochemistry and Photobiology B: Biology 177: 39-43. https://doi.org/10.1016/j.jphotobiol.2017.10.014.

de Mello Gallep, C. and Robert, D., 2020. Time-resolved ultra-weak photon emission as germination performance indicator in single seedlings. Journal of photochemistry and photobiology 1: 100001. https://doi.org/10.1016/j.jpap.2020.100001

Egawa, M., Kohno, Y. and Kumano, Y., 1999. Oxidative effects of cigarette smoke on the human skin. International Journal of Cosmetic Science 21(2): 83-98. https://doi. org/10.1046/j.14.67-24.94.1999.181656.x

El-Mesery, H.S., Mao, H. and Abomohra, A.E.-F., 2019. Applications of nondestructive technologies for agricultural and food products quality inspection. Sensors 19(4): 846. https://doi. org/10.3390/s19040846

Esmaeilpour, T., Fereydouni, E., Dehghani, F., Bókkon, I., Panjehshahin, M.-R., Császár-Nagy, N., Ranjbar, M. and Salari, V., 2020. An experimental investigation of ultraweak photon emission from adult murine neural stem cells. Scientific Reports 10: 1-13. https://doi.org/10.1038/s41598-019-57352-4.

Evelson, P., Ordóñez, C.P., Llesuy, S. and Boveris, A., 1997. Oxidative stress and in vivo chemiluminescence in mouse skin exposed to UVA radiation. Journal of Photochemistry and Photobiology B: Biology 38(2-3): 215-219. https://doi. org/10.1016/S1011-1344.(96)07437-4

Fedorova, G.F., Trofimov, A.V., Vasil'ev, R.F. and Veprintsev, T.L., 2007. Peroxy-radical-mediated chemiluminescence: mechanistic diversity and fundamentals for antioxidant assay. Arkivoc 8, 163-215. https://doi.org/10.3998/ark.5550190.0008.815

Gałązka-Czarnecka, I., Korzeniewska, E., Czarnecki, A., Sójka, M., Kiełbasa, P. and Dróżdź, T., 2019. Evaluation of quality of eggs from hens kept in caged and free-range systems using traditional methods and ultra-weak luminescence. Applied Sciences 9(12): 2430. https://doi.org/10.3390/app9122430

Gallep, C., Conforti, E., Braghini, M., Maluf, M., Yan, Y. and Popp, F., 2004. Ultra-weak delayed luminescence in coffee seeds
(Coffea arabica and C. canephora) and their germination potential: some indications for a photonic approach in seed viability. Proceedings of 11th Brazilian Symposium of Microwave and Optoeletronics, São Paulo, Brazil, section p1-12.

Gallep, C. and Dos Santos, S., 2007. Photon-counts during germination of wheat (Triticum aestivum) in wastewater sediment solutions correlated with seedling growth. Seed Science and Technology 35(3): 607-614. https://doi.org/10.15258/ sst.2007.35.3.08

Gill, S.S. and Tuteja, N., 2010. Reactive oxygen species and antioxidant machinery in abiotic stress tolerance in crop plants. Plant Physiology and Biochemistry 48(12): 909-930. https://doi. org/10.1016/j.plaphy.2010.08.016

Giovenzana, V., Beghi, R., Civelli, R., Trapani, S., Migliorini, M., Cini, E., Zanoni, B. and Guidetti, R., 2017. Rapid determination of crucial parameters for the optimization of milling process by using visible/near infrared spectroscopy on intact olives and olive paste. Italian Journal of Food Science 29(2): 357-369. https://doi.org/10.14674/1120-1770/ijfs.v560

Godfray, H.C.J., Beddington, J.R., Crute, I.R., Haddad, L., Lawrence, D., Muir, J.F., Pretty, J., Robinson, S., Thomas, S.M. and Toulmin, C., 2010. Food security: the challenge of feeding 9 billion people. Science 327(5967): 812-818. https://doi. org/10.1126/science.1185383

Grashorn, M.A. and Egerer, U., 2007. Integrated assessment of quality of chicken organic eggs by measurement of dark luminescence. Polish Journal of Food and Nutrition Sciences 57(4 [A]): 191-194.

Grasso, R., Gulino, M., Giuffrida, F., Agnello, M., Musumeci, F. and Scordino, A., 2018. Nondestructive evaluation of watermelon seeds germination by using delayed luminescence. Journal of Photochemistry and Photobiology B: Biology 187: 126-130. https://doi.org/10.1016/j.jphotobiol.2018.08.012

$\mathrm{Gu}, \mathrm{Q} ., 1999$. On coherence theory of biophoton emission. Journal of the GCPD eV 5(17): 17-20.

Guo, J., Zhu, G., Li, L., Liu, H. and Liang, S., 2017. Ultraweak photon emission in strawberry fruit during ripening and aging is related to energy level. Open Life Sciences 12(1): 393-398. https://doi. org/10.1515/biol-2017-0046

Guo, Y. and Tan, J., 2013. A biophotonic sensing method for plant drought stress. Sensors and Actuators B: Chemical 188: 519524. https://doi.org/10.1016/j.snb.2013.07.020

Gupta, D.K., Palma, J.M. and Corpas, F.J., 2015. Reactive oxygen species and oxidative damage in plants under stress. Springer. Cham, Switzerland.

Hossu, M., Ma, L. and Chen, W., 2010. Nonlinear enhancement of spontaneous biophoton emission of sweet potato by silver nanoparticles. Journal of Photochemistry and Photobiology B: Biology 99: 44-48. https://doi.org/10.1016/j. jphotobiol.2010.02.002

Inagaki, H., Imaizumi, T., Wang, G.-X., Tominaga, T., Kato, K., Iyozumi, H. and Nukui, H., 2007. Spontaneous ultraweak photon emission from rice (Oryza sativa L.) and paddy weeds treated with a sulfonylurea herbicide. Pesticide Biochemistry and Physiology 89(2): 158-162. https://doi.org/10.1016/j. pestbp.2007.05.005 
Inagaki, H., Imaizumi, T., Wang, G.-X., Tominaga, T., Kato, K., Iyozumi, H. and Nukui, H., 2009. Sulfonyl urea-resistant biotypes of Monochoria vaginalis generate higher ultraweak photon emissions than the susceptible ones. Pesticide Biochemistry and Physiology 95(3): 117-120. https://doi.org/10.1016/j. pestbp. 2009.08.002

Inagaki, H., Ishida, Y., Uchino, A., Kato, K., Kageyama, C., Iyozumi, H. and Nukui, H., 2008. Difference in ultraweak photon emissions between sulfonylurea-resistant and sulfonylurea-susceptible biotypes of Scirpus juncoides following the application of a sulfonylurea herbicide. Weed Biology and Management 8(2): 78-84. https://doi.org/10.1111/j.1445-6664.2008.00278.x

Iyozumi, H., Kato, K. and Makino, T., 2002. Spectral shift of ultraweak photon emission from sweet potato during a defense response. Photochemistry and Photobiology 75(3): 322-325. https://doi.org /10.1562/0031-8655(2002)075\%3C0322:SSOUPE\%3E2.0.CO;2

Janků, M., Luhová, L. and Petřivalský, M., 2019. On the origin and fate of reactive oxygen species in plant cell compartments. Antioxidants 8(4): 105. https://doi.org/10.3390/antiox8040105

Jia, Y., Sun, M., Shi, Y., Zhu, Z., van Wijk, E., van Wijk, R., van Andel, T. and Wang, M., 2020. A comparative study of aged and contemporary Chinese herbal materials by using delayed luminescence technique. Chinese medicine 15: 6. https://doi. org/10.1186/s13020-020-0287-0

Kageyama, C., Kato, K., Iyozumi, H., Inagaki, H., Yamaguchi, A., Furuse, K. and Baba, K., 2006. Photon emissions from rice cells elicited by $\mathrm{N}$-acetylchitooligosaccharide are generated through phospholipid signaling in close association with the production of reactive oxygen species. Plant Physiology and Biochemistry 44(11-12): 901-909. https://doi.org/10.1016/j. plaphy.2006.09.010

Kamal, A.H.M. and Komatsu, S., 2016. Proteins involved in biophoton emission and flooding-stress responses in soybean under light and dark conditions. Molecular Biology Reports 43(2): 73-89. https://doi.org/10.1007/s11033-015-394.0-4

Karuppanapandian, T., Moon, J.-C., Kim, C., Manoharan, K. and Kim, W., 2011. Reactive oxygen species in plants: their generation, signal transduction, and scavenging mechanisms. Australian Journal of Crop Science 5(6): 709.

Kato, K., Iyozumi, H., Kageyama, C., Inagaki, H., Yamaguchi, A. and Nukui, H., 2014. Application of ultra-weak photon emission measurements in agriculture. Journal of Photochemistry and Photobiology B: Biology 139: 54-62. https://doi.org/10.1016/j. jphotobiol.2014.06.010

Kausar, R., Hossain, Z., Makino, T. and Komatsu, S., 2012. Characterization of ascorbate peroxidase in soybean under flooding and drought stresses. Molecular Biology Reports 39(12): 10573-10579. https://doi.org/10.1007/s11033-012-1945-9

Kehrer, J.P., 2000. The Haber-Weiss reaction and mechanisms of toxicity. Toxicology 149(1): 43-50. https://doi.org/10.1016/ S0300-483X(00)00231-6

Khatoon, A., Rehman, S., Hiraga, S., Makino, T. and Komatsu, S., 2012. Organ-specific proteomics analysis for identification of response mechanism in soybean seedlings under flooding stress. Journal of Proteomics 75(18): 5706-5723. https://doi. org/10.1016/j.jprot.2012.07.031
Kheiralipour, K., Ahmadi, H., Rajabipour, A., Rafiee, S., JavanNikkhah, M., Jayas, D. and Siliveru, K., 2016. Detection of fungal infection in pistachio kernel by long-wave near-infrared hyperspectral imaging technique. Quality Assurance and Safety of Crops and Foods 8(1): 129-135. https://doi.org/10.3920/ QAS2015.0606

Kobayashi, M., Sasaki, K., Enomoto, M. and Ehara, Y., 2006. Highly sensitive determination of transient generation of biophotons during hypersensitive response to cucumber mosaic virus in cowpea. Journal of Experimental Botany 58(3): 465-472. https:// doi.org/10.1093/jxb/erl215

Komatsu, S., Kamal, A.H.M., Makino, T. and Hossain, Z., 2014. Ultraweak photon emission and proteomics analyses in soybean under abiotic stress. Biochimica et Biophysica Acta (BBA)Proteins and Proteomics 1844(7): 1208-1218.

Krieger-Liszkay, A., 2005. Singlet oxygen production in photosynthesis. Journal of Experimental Botany 56(411): 337-346.

Lambing, K., 1992. Biophoton measurement as a supplement to the conventional consideration of food quality. In: Popp, F. A., Li, K. H. and Gu, Q. (eds) Recent advances in biophoton research and its applications. World Scientific, Singapore, Singapore, pp. 393-413.

Liang, X., Wang, Z., Gao, M., Wu, S., Zhang, J., Liu, Q., Yu, Y., Wang, J. and Liu, W., 2019. Cyclic stretch-induced oxidative stress by mitochondrial and NADPH oxidase in retinal pigment epithelial cells. BMC Ophthalmology 19(1): 79. https://doi. org/10.1186/s12886-019-1087-0

Madl, P., 2014. Detection and measurement of biogenic ultra-weak photon emission. In: Fels, D., Cifra, M. and Scholkmann, F. (eds.) Field of the cells. Research Signpost, Trivandrum, Kerala, India. pp. 55-70.

Magwaza, L.S., Ford, H.D., Cronje, P.J., Opara, U.L., Landahl, S., Tatam, R.P. and Terry, L.A., 2013. Application of optical coherence tomography to non-destructively characterise rind breakdown disorder of 'Nules Clementine' mandarins. Postharvest Biology and Technology 84: 16-21. https://doi.org/10.1016/j. postharvbio.2013.03.019

Makino, T., Kato, K., Lyozumi, H., Honzawa, H., Tachiiri, Y. and Hiramatsu, M., 1996. Ultraweak luminescence generated by sweet potato and Fusarium oxysporum interactions associated with a defense response. Photochemistry and Photobiology 64(6): 953-956. https://doi.org/10.1111/j.1751-1097.1996.tb01860.x

Mansfield, J.W., 2005. Biophoton distress flares signal the onset of the hypersensitive reaction. Trends in Plant Science 10(7): 307309. https://doi.org/10.1016/j.tplants.2005.05.007

Mayorga Burrezo, P., Jiménez, V.G., Blasi, D., Ratera, I., Campaña, A.G. and Veciana, J., 2019. Organic free radicals as circularly polarized luminescence emitters. Angewandte Chemie (International Edition) 58(45): 16282-16288. https:// doi.org/10.1002/anie.201909398

McCaig, C.D., Rajnicek, A.M., Song, B. and Zhao, M., 2005. Controlling cell behavior electrically: current views and future potential. Physiological Reviews 85(3): 943-978. https://doi. org/10.1152/physrev.00020.2004

McCarthy, U., Uysal, I., Melis, R.B., Mercier, S., Donnell, C.O. and Ktenioudaki, A., 2018. Global food security-issues, challenges 
and technological solutions. Trends in Food Science and Technology 77: 11-20. https://doi.org/10.1016/j.tifs.2018.05.002 Montillet, J.-L., Chamnongpol, S., Rustérucci, C., Dat, J., Van De Cotte, B., Agnel, J.-P., Battesti, C., Inzé, D., Van Breusegem, F. and Triantaphylides, C., 2005. Fatty acid hydroperoxides and $\mathrm{H}_{2} \mathrm{O}_{2}$ in the execution of hypersensitive cell death in tobacco leaves. Plant Physiology 138(3): 1516-1526. https://doi. org/10.1104/pp.105.059907

Moraes, T.A., Barlow, P.W., Klingelé, E. and Gallep, C.M., 2012. Spontaneous ultra-weak light emissions from wheat seedlings are rhythmic and synchronized with the time profile of the local gravimetric tide. Naturwissenschaften 99(6): 465-472. https:// doi.org/10.1007/s00114-012-0921-5

Mousavi Khaneghah, A., 2016. An overview on some of important sources of natural antioxidants. International Food Rresearch Journal 23(3): 928-933.

Münzel, T., Sørensen, M., Schmidt, F., Schmidt, E., Steven, S., Kröller-Schön, S. and Daiber, A., 2018. The adverse effects of environmental noise exposure on oxidative stress and cardiovascular risk. Antioxidants and Redox Signaling 28(9): 873-908. https://doi.org/10.1089/ars.2017.7118

Nakashima, Y., Ohta, S. and Wolf, A.M., 2017. Blue light-induced oxidative stress in live skin. Free Radical Biology and Medicine 108: 300-310. https://doi.org/10.1016/j. freeradbiomed.2017.03.010

Nawara, P., Gliniak, M., Popardowski, E., Szczuka, M. and Trzyniec, K., 2018. Control system of a prototype measurement system for the identification of ultra-low photonic emission of organic materials. Progress in Applied Electrical Engineering (PAEE), June 18-22, 2018. Koscielisko, Poland, pp. 35-37.

Nukui, H., Inagaki, H., Iyozumi, H. and Kato, K., 2013. Biophoton emissions in sulfonylureaherbicide-resistant weeds. In: Herbicides-advances in research, InTech Open Science, Rijeka, Croatia, pp. 219-235. http://dx.doi.org/10.5772/55846

Ohya, T., Kurashige, H., Okabe, H. and Kai, S., 2000. Early detection of salt stress damage by biophotons in red bean seedling. Japanese Journal of Applied Physics 39(6R): 3696. https://doi. org/10.1143/JJAP.39.3696

Ohya, T., Yoshida, S., Kawabata, R., Okabe, H. and Kai, S., 2002. Biophoton emission due to drought injury in red beans: possibility of early detection of drought injury. Japanese Journal of Applied Physics 41(7R): 4766. https://doi.org/10.1143/JJAP.41.4766

Omar, A. and MatJafri, M., 2013. Principles, methodologies and technologies of fresh fruit quality assurance. Quality Assurance and Safety of Crops and Foods 5(3): 257-271. https://doi. org/10.3920/QAS2012.0175

Ortega-Ojeda, F., Calcerrada, M., Ferrero, A., Campos, J. and Garcia-Ruiz, C., 2018. Measuring the human ultra-weak photon emission distribution using an electron-multiplying, charge-coupled device as a sensor. Sensors 18(4): 1152. https:// doi.org/10.3390/s18041152

Pitzschke, A., Forzani, C. and Hirt, H., 2006. Reactive oxygen species signaling in plants. Antioxidants and Redox Signaling 8(910): 1757-1764. https://doi.org/10.1089/ars.2006.8.1757

Pospíšil, P., Prasad, A. and Rác, M., 2014. Role of reactive oxygen species in ultra-weak photon emission in biological systems.
Journal of Photochemistry and Photobiology B: Biology 139: 11-23. https://doi.org/10.1016/j.jphotobiol.2014.02.008

Pospíšil, P., Prasad, A. and Rác, M., 2019. Mechanism of the formation of electronically excited species by oxidative metabolic processes: role of reactive oxygen species. Biomolecules 9(7): 258. https://doi.org/10.3390/biom9070258

Prasad, A., Gouripeddi, P., Devireddy, H.R.N., Ovsii, A., Rachakonda, D.P., Wijk, R.V. and Pospíšil, P., 2020. Spectral Distribution of Ultra-Weak Photon Emission as a Response to Wounding in Plants: An In Vivo Study. Biology 9: 139. https:// doi.org/10.3390/biology9060139

Prasad, A. and Pospíšil, P., 2011. Linoleic acid-induced ultra-weak photon emission from Chlamydomonas reinhardtii as a tool for monitoring of lipid peroxidation in the cell membranes. PLoS One 6(7): 1-10. https://doi.org/10.1371/journal.pone.0022345

Prasad, A., Rossi, C., Lamponi, S., Pospíšil, P. and Foletti, A., 2014. New perspective in cell communication: Potential role of ultra-weak photon emission. Journal of Photochemistry and Photobiology B: Biology 139: 47-53. https://doi.org/10.1016/j. jphotobiol.2014.03.004

Prosekov, A.Y. and Ivanova, S.A., 2018. Food security: the challenge of the present. Geoforum 91: 73-77. https://doi.org/10.1016/j. geoforum.2018.02.030

Racchi, M.L., 2013. Antioxidant defenses in plants with attention to Prunus and Citrus spp. Antioxidants 2(4): 340-369. https://doi. org/10.3390/antiox2040340

Rafii-Tabar, H. and Rafieiolhosseini, N., 2015. Different aspects of ultra-weak photon emissions: a review article. Iranian Journal of Medical Physics 12(3): 137-144.

Rahnama, M., Tuszynski, J.A., Bokkon, I., Cifra, M., Sardar, P. and Salari, V., 2011. Emission of mitochondrial biophotons and their effect on electrical activity of membrane via microtubules. Journal of Integrative Neuroscience 10(1): 65-88. https://doi. org/10.1142/S0219635211002622

Rastogi, A. and Pospíšil, P., 2010. Effect of exogenous hydrogen peroxide on biophoton emission from radish root cells. Plant physiology and biochemistry 48: 117-123. https://doi.org/10.1016/j. plaphy.2009.12.01

Rastogi, A. and Pospísil, P., 2011. Spontaneous ultraweak photon emission imaging of oxidative metabolic processes in human skin: effect of molecular oxygen and antioxidant defense system. Journal of Biomedical Optics 16(9): 096005. https://doi. org/10.1117/1.3616135

Rastogi, A. and Pospíšil, P., 2012. Production of hydrogen peroxide and hydroxyl radical in potato tuber during the necrotrophic phase of hemibiotrophic pathogen Phytophthora infestans infection. Journal of Photochemistry and Photobiology B: Biology 117: 202-206. https://doi.org/10.1016/j.jphotobiol.2013.03.012

Saeidfirozeh, H., Shafiekhani, A., Cifra, M. and Masoudi, A.A., 2018. Endogenous chemiluminescence from germinating arabidopsis thaliana seeds. Scientific Reports 8(1): 1-10. https://doi. org/10.1038/s41598-018-34485-6

Saikolappan, S., Kumar, B., Shishodia, G., Koul, S. and Koul, H.K., 2019. Reactive oxygen species and cancer: a complex interaction. Cancer Letters 452: 132-143. https://doi.org/10.1016/j. canlet.2019.03.020 
Salari, V., Tuszynski, J., Bokkon, I., Rahnama, M. and Cifra, M., 2011. On the photonic cellular interaction and the electric activity of neurons in the human brain. Journal of Physics: Conference Series 329:1-9. https://doi.org/10.1088/1742-6596/329/1/012006

Salari, V., Valian, H., Bassereh, H., Bókkon, I. and Barkhordari, A., 2015. Ultraweak photon emission in the brain. Journal of Integrative Neuroscience 14(3): 419-429. https://doi. org/10.1142/S0219635215300012

Sauermann, G., Mei, W.P., Hoppe, U. and Stäb, F., 1999. Ultraweak photon emission of human skin in vivo: influence of topically applied antioxidants on human skin. In: Packer, L. (ed.) Methods in enzymology, Vol. 300. Elsevier, Amsterdam, the Netherlands, pp. 419-428.

Schinabeck, T.-M., Weigler, F., Flöter, E. and Mellmann, J., 2018. Variability in determination of the single kernel moisture content of grain by means of TD-NMR spectroscopy. Quality Assurance and Safety of Crops and Foods 10(1): 75-82. https:// doi.org/10.3920/QAS2017.1149

Scholkmann, F., Fels, D. and Cifra, M., 2013. Non-chemical and non-contact cell-to-cell communication: a short review. American Journal of Translational Research 5(6): 586.

Shanei, A., Alinasab, Z., Kiani, A. and Nematollahi, M., 2017. Detection of ultraweak photon emission (UPE) from cells as a tool for pathological studies. Journal of Biomedical Physics and Engineering 7(4): 389.

Sies, H., Berndt, C. and Jones, D.P., 2017. Oxidative stress. Annual Review of Biochemistry 86: 715-748. https://doi.org/10.1146/ annurev-biochem-061516-045037

Singh, A., Yashavarddhan, M., Kalita, B., Ranjan, R., Bajaj, S., Prakash, H. and Gupta, M.L., 2017. Podophyllotoxin and rutin modulates ionizing radiation-induced oxidative stress and apoptotic cell death in mice bone marrow and spleen. Frontiers in Immunology 8: 183. https://doi.org/10.3389/fimmu.2017.00183

Slawinska, D. and Slawinski, J., 1997. Chemiluminescence of cereal products I. Kinetics, activation energy and effect of solvents. Journal of Bioluminescence and Chemiluminescence 12(5): 249-259. https://doi.org/10.1002/(SICI)1099-1271(199709/10) 12:5\%3C249::AID-BIO453\%3E3.0.CO;2-X

Slawinska, D. and Sławinski, J., 1998. Chemiluminescence of cereal products III. Two-dimensional photocount imaging of chemiluminescence. Journal of Bioluminescence and Chemiluminescence 13(1): 21-24. https://doi.org/10.1002/ (SICI)1099-1271(199801/02)13:1\%3C21::AID-IO462\%3E3.0. $\mathrm{CO} ; 2-\mathrm{H}$

Sun, M., Wang, S., Jing, Y., Li, L., He, M., Jia, Y., van Wijk, E., Wang, Y., Wang, Z. and Wang, M., 2019. Application of delayed luminescence measurements for the identification of herbal materials: a step toward rapid quality control. Chinese Medicine 14(1): 1-13. https://doi.org/10.1186/s13020-019-0269-2

Thannickal, V.J. and Fanburg, B.L., 2000. Reactive oxygen species in cell signaling. American Journal of Physiology-Lung Cellular and Molecular Physiology 279(6): L1005-L1028. https://doi. org/10.1152/ajplung.2000.279.6.L1005
Triglia, A., La Malfa, G., Musumeci, F., Leonardi, C. and Scordino, A., 1998. Delayed luminescence as an indicator of tomato fruit quality. Journal of Food Science 63(3): 512-515. https://doi.org/10.1111/j.1365-2621.1998.tb15775.x

Tripathy, B.C. and Oelmüller, R., 2012. Reactive oxygen species generation and signaling in plants. Plant Signaling and Behavior 7(12): 1621-1633. https://doi.org/10.4161/psb.22455

Tsuchida, K., Iwasa, T. and Kobayashi, M., 2019. Imaging of ultraweak photon emission for evaluating the oxidative stress of human skin. Journal of Photochemistry and Photobiology B: Biology 198: 111562. https://doi.org/10.1016/j. jphotobiol.2019.111562

Tsugane, K., Kobayashi, K., Niwa, Y., Ohba, Y., Wada, K. and Kobayashi, H., 1999. A recessive Arabidopsis mutant that grows photoautotrophically under salt stress shows enhanced active oxygen detoxification. The Plant Cell 11(7): 1195-1206. https:// doi.org/10.1105/tpc.11.7.1195

Van Wijk, R., 2001. Bio-photons and bio-communication. Journal of Scientific Exploration 15(2): 183-197.

Van Wijk, E.P., Van Wijk, R. and Bosman, S., 2010. Using ultraweak photon emission to determine the effect of oligomeric proanthocyanidins on oxidative stress of human skin. Journal of Photochemistry and Photobiology B: Biology 98(3): 199-206. https://doi.org/10.1016/j.jphotobiol.2010.01.003

Velimirov, A., 2005. The consistently superior quality of carrots from one organic farm in Austria compared with conventional farms. Proccedings of the 15th IFOAM Organic World Congress "Researching and Shaping Sustainable Systems", September 21-23, 2005, Adelaide, pp. 1-4.

Wang, J. and Yu, Y., 2009. Relationship between ultra-weak bioluminescence and vigour or irradiation dose of irradiated wheat. Luminescence: The Journal of Biological and Chemical Luminescence 24(4): 209-212. https://doi.org/10.1002/bio.1096

Xu, Y., Song, W., Zhou, P., Li, P. and Li, H., 2015. Morphological and microscopic characterization of five commonly used testacean traditional Chinese medicines. Acta Pharmaceutica Sinica B 5(4): 358-366. https://doi.org/10.1016/j.apsb.2015.03.014

Yang, M., Ding, W., Liu, Y., Fan, H., Bajpai, R.P., Fu, J., Pang, J., Zhao, X. and Han, J., 2017. Ultra-weak photon emission in healthy subjects and patients with type 2 diabetes: evidence for a non-invasive diagnostic tool. Photochemical and Photobiological Sciences 16(5): 736-743. https://doi.org/10.1039/C6PP00431H

Yang, M., Pang, J., Liu, J., Liu, Y., Fan, H. and Han, J., 2015. Spectral discrimination between healthy people and cold patients using spontaneous photon emission. Biomedical Optics Express 6(4): 1331-1339. https://doi.org/10.1364/BOE.6.001331

Yoshinaga, N., Kato, K., Kageyama, C., Fujisaki, K., Nishida, R. and Mori, N., 2006. Ultraweak photon emission from herbivory-injured maize plants. Naturwissenschaften 93(1): 38-41. https:// doi.org/10.1007/s00114-005-0059-9

Zhong, J. and Wang, X., 2019. An introduction to evaluation technologies for food quality. In: Evaluation technologies for food quality. Woodhead Publishing, Duxford, UK, pp. 1-3. 